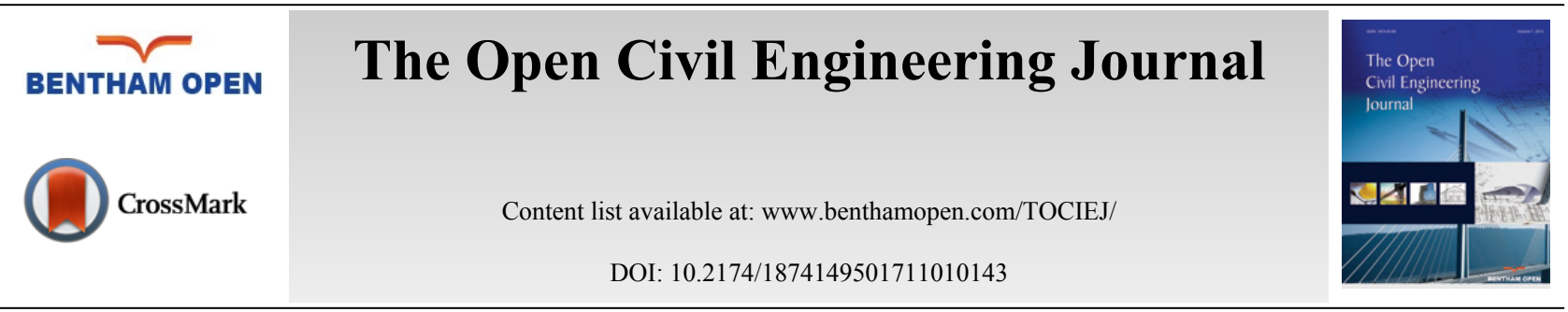

RESEARCH ARTICLE

\title{
Interaction between Internal Shear Reinforcement and External FRP Systems of RC Beams: Experimental Study
}

\author{
Wee Teo ${ }^{1}$, Kilian Lau Meow Hing ${ }^{2}$ and Mohd Shahir Liew, ${ }^{2, *}$ \\ ${ }^{1}$ Heriot Watt University, Malaysia No 1, Jalan Venna P5/2 Precinct 5 62200, Putrajaya, Malaysia \\ ${ }^{2}$ University Technology Petronas, Bandar Seri Iskandar, 32610 Tronoh, Perak Darul Ridzuan, Malaysia
}

Received: October 14, 2015

Revised: March 09, 2016

Accepted: May 20, 2016

\begin{abstract}
Extensive research effort has been conducted on the shear strengthening of reinforced concrete (RC) beams with externally bonded FRP systems. However, there are still few aspects on their behaviour that are yet to be fully understood. One of them is the effect of shear interaction between internal transverse shear reinforcement and the external FRP systems. This paper is intended to study experimentally the interaction between these two shear reinforcement components. To do so, a total of five concrete beams were assembled in this investigation. All beams were properly instrumented in order to obtain as much data as possible. Four beams were externally strengthened with FRP with different strengthening and wrapping schemes. Their influence and interaction with the internal transverse stirrups in shear resistance were discussed based on the modes of failure exhibited, deflection and strain (steel and FRP) responses. Overall the results obtained are in good agreement with many researches which indicated that addition of externally bonded FRP, as a matter of fact, preserves the integrity of internal transverse stirrups. With continuous FRP sheets and U-wrapped scheme, greater FRP contribution to the shear resistance can be expected.
\end{abstract}

Keywords: Beams, Concrete, FRP, Interaction, Reinforcement, Shear, Stirrups, Strengthening.

\section{INTRODUCTION}

Shear failure in reinforced concrete (RC) is catastrophic and sudden in nature, therefore should be avoided in all time. It is a complex and controversial subject and despite extensive experimental research [1], until now it still remains not fully resolved and understood.

Many existing RC structures are prone to deficient in shear strength and are in need for strengthening. The shear strength of RC beams can be enhanced by externally bonded FRP systems, which may consist of either strips or continuous sheets. The FRP system can be fully wrapped, U-wrapped or 2-sides bonded. But for typical beam element with slab on top, U-wrapped and 2-sides bonded are more common.

Over the years, extensive research effort has been conducted on the shear strengthening of RC beams with externally bonded FRP systems. Despite that still, there are some inconclusive understandings on the behaviour of shear strengthened beams. One in particular is regarding the interaction between the internal shear reinforcement (transverse stirrups) and the external FRP reinforcement [2 - 9].

In the current shear design provision on externally bonded FRP system [10 - 13], the nominal shear strength $V_{n}$ of the strengthened members is expressed as the summation of shear strength contributed by concrete $\left(\mathrm{V}_{c}\right)$, internal shear reinforcement $\left(\mathrm{V}_{\mathrm{s}}\right)$ and external FRP systems $\left(\mathrm{V}_{\mathrm{frp}}\right)$. Each of the components is assumed to contribute independently to shear resistance and reaches their respective maximum values simultaneously at the shear failure [2]. However, this scenario might not be true. Previous research $[7,8]$ has found that the effectiveness of FRP shear contribution actually

* Address correspondence to this author at the University Technology Petronas, Bandar Seri Iskandar, 32610 Tronoh, Perak Darul Ridzuan, Malaysia; Tel: +605-368 7117; E-mail: shahir_liew@petronas.com.my 
decreases with an increase in the amount of internal shear reinforcement.

The purpose of this paper is to present some of the preliminary results obtained experimentally on the shear interaction between the internal stirrups and the external FRP systems. The behaviour of the strengthened beams is explained by means of strain responses between internal stirrups and external FRP, and also the overall deflection response of the beam.

\section{MECHANISMS OF SHEAR RESISTANCE OF EXTERNALLY BONDED FRP SHEAR STRENGTHENED RC BEAMS}

In the current design guidelines on FRP shear strengthening, the ultimate shear strength of the FRP strengthened RC beam is formed by superimposing the shear resistance of concrete, internal steel stirrups and externally bonded FRP. Each shear component contributes to shear resistance independently, without taking into consideration the interaction between each other. Fig. (1) shows the response of different components of shear resistance in relation to the critical shear crack development. Generally, it can be observed that at the ultimate stage, all three shear components do not reach to their ultimate strength simultaneously. For instance when the externally bonded FRP reach to its maximum value, the shear resistance of the internal stirrups is still significantly lower. Internal steel stirrups which are intersected by major shear crack may not reach yield when it reaches to its ultimate failure load $[2,3]$.

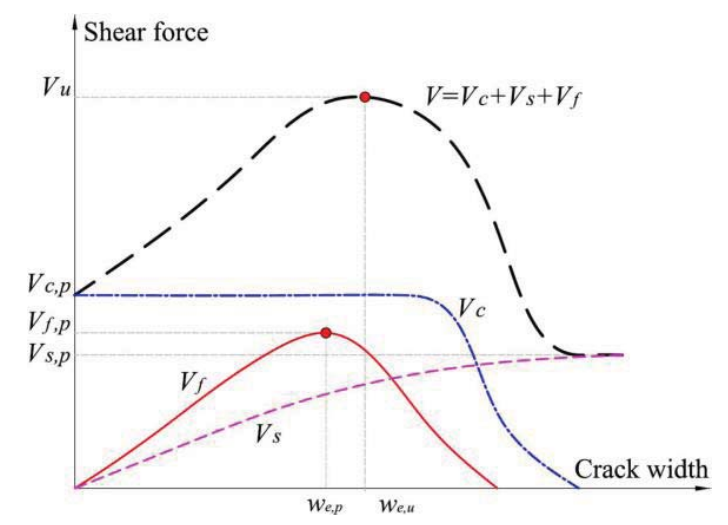

Fig. (1). Development of different components of shear resistance with the crack end width of the critical shear crack [3].

Grande et al. [14] carried out an experimental investigation into the influence of transverse steel reinforcement on the contribution of FRP to the shear resistance. Fifteen RC beams were manufactured; each beam varies in terms of the amount of transverse steel ratio provided and FRP strengthening schemes. Their test results indicated that the contribution of FRP to the shear resistance actually reduces when the amount of transverse steel ratio increases. Similar findings are also reported by other researchers $[5,6,9]$. Grande et al. also observed that the internal stirrups only yield in the beams with an internal spacing greater than $200 \mathrm{~mm}$.

Meanwhile, Pellegrino et al. [15] stated that concrete cracking has a significant effect on the effectiveness of shear strengthening with externally bonded FRP when transverse steel reinforcement is presence. Similar findings were also reported by Chen et al. [2,3]. They indicated that the main reason for causing FRP debonding in a brittle manner is due to the effect of shear crack widening.

Mofidi et al. $[4,6]$ have highlighted the major parameters that influence the shear strengthening of RC beams with externally bonded FRP. The effect of transverse steel reinforcement on the shear contribution of FRP was found to be significant. None of the current design guidelines have considered the effect of transverse steel in the calculation of the FRP shear contribution. Mofidi et al. have found that the presence of transverse steel reinforcement significantly reduces the FRP contribution to shear resistance. Their experimental tests indicated that externally FRP strengthening does not avoid the internal transverse steel reinforcement from yielding. It would yield provided that it is across by the major shear crack.

From the available literature, it is evident that the transverse steel reinforcement has a significant effect on the FRP contribution to the shear resistance. Until now, it is yet to reach a common agreement on the understanding of the interaction between the transverse steel reinforcement and externally bonded FRP. More researches are still needed to 
develop a better understanding.

\section{EXPERIMENTAL PROGRAMME}

As the main objective of this paper is to investigate experimentally the shear interaction between internal stirrups and external FRP systems, five rectangular reinforced concrete (RC) beams were prepared in the programme. All beams were provided with the similar amount of transverse stirrups throughout the shear span. One of the beams served as the control specimen, whereas remaining four beams were strengthened with externally bonded CFRP systems. Descriptions of the beam specimens, test setup and instrumentation are explained in the subsequent sections.

\subsection{Description of Beam Specimens}

The beams are $2000 \mathrm{~mm}$ long with rectangular cross-sectional dimensions of $150 \mathrm{~mm}$ wide by $250 \mathrm{~mm}$ height. All beams are reinforced with longitudinal reinforcement consisting of four T16 diameter high tensile steel bars $\left(4 \mathrm{~T} 16, \mathrm{~A}_{\mathrm{s}}=\right.$ $\left.804.25 \mathrm{~mm}^{2}\right)$ arranged in two layers at the bottom, and two T10 diameter high tensile steel bars $\left(2 \mathrm{~T} 10, \mathrm{~A}^{\prime}{ }_{\mathrm{s}}=157.08\right.$ $\mathrm{mm}^{2}$ ) at the top, see Fig. (2). The design of the reinforcement is to prevent flexural yielding of the steel bar and to ensure shear failure occur along the beam's shear span. The nominal amount of shear reinforcement is also provided along the shear span for this study. The transverse stirrups provided are R6 diameter mild steel bars with $200 \mathrm{~mm}$ spacing centre-to-centre $\left(A_{v}=56.55 \mathrm{~mm}^{2}\right)$, which corresponds to transverse stirrup ratio of $0.19 \%$. The yield strength for T16, T10 and R6 are $622.5 \mathrm{~N} / \mathrm{mm}^{2}, 412.7 \mathrm{~N} / \mathrm{mm}^{2}$ and $250 \mathrm{~N} / \mathrm{mm}^{2}$ respectively.

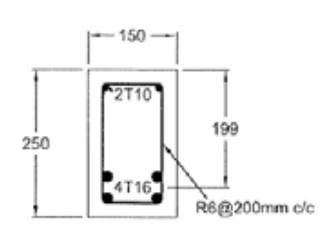

FRP strengthening schemes
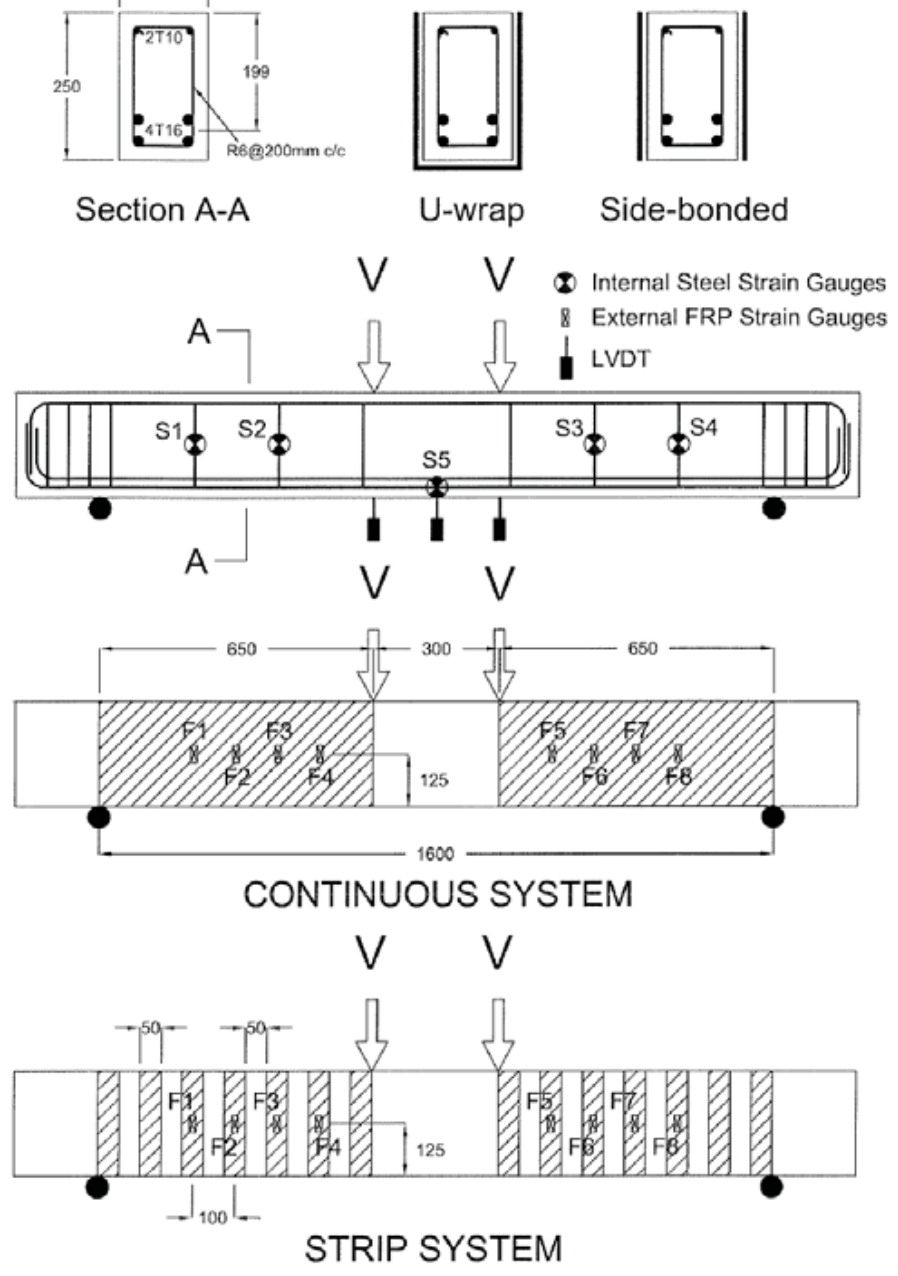

Fig. (2). Details of the beam specimen, test setup and instrumentation.

In this work, the concrete is supplied by a local ready-mix supplier. All beams are cast from the same concrete 
batch. Six numbers of 100 by $200 \mathrm{~mm}$ standard cylinders and $100 \mathrm{~mm}$ cubes are prepared for the compression test purpose. The cylinders and cubes are all cured under identical conditions as the beam specimens: that is under normal room temperature covered with wet hessian for 7 days and followed by dry open air for the remainder period until the day of testing. The average concrete compressive strength obtained for cylinders and cubes at 28 -days are $22.73 \mathrm{~N} / \mathrm{mm}^{2}$ and $32.5 \mathrm{~N} / \mathrm{mm}^{2}$ respectively. It should be noted that all beam specimens were tested at around 90 -days due to the maintenance of the laboratory testing frame. However, it is believed that the effect of this is insignificant.

\subsection{CFRP Strengthening Schemes}

Five beam specimens are assembled in this experimental programme. Details of each beam designation are summarised in Table 1. The control beam without CFRP strengthening is designated as "B1", whereas the remainder four strengthened beam specimens are designated according to the type of wrapping schemes and strengthening arrangement.

Table 1. Experimental results.

\begin{tabular}{|c|c|c|c|c|c|c|c|c|c|}
\hline Specimen & $\begin{array}{c}\mathbf{w}_{\mathrm{f}} \\
{[\mathrm{mm}]}\end{array}$ & $\begin{array}{c}\mathbf{s}_{\mathrm{f}} \\
{[\mathrm{mm}]}\end{array}$ & $\mathbf{w}_{\mathrm{f}} / \mathbf{s}_{\mathrm{f}}$ & $\begin{array}{c}\text { No of days to } \\
\text { testing }\end{array}$ & $\begin{array}{l}\mathbf{V}_{\mathrm{u}, \exp } \\
{[\mathrm{kN}]}\end{array}$ & $\begin{array}{c}\mathbf{V}_{\mathrm{c}}+\mathrm{V}_{\mathrm{s}} \\
{[\mathrm{kN}]}\end{array}$ & $\begin{array}{c}\mathbf{V}_{\text {frp }} \\
{[\mathrm{kN}]}\end{array}$ & $\begin{array}{c}\text { \% gain due to } \\
\text { CFRP }\end{array}$ & $\begin{array}{l}\text { Mode of } \\
\text { failure }\end{array}$ \\
\hline B1 & N/A & N/A & N/A & 87 & 73.57 & 73.57 & 0 & 0 & $\mathrm{~S}$ \\
\hline B1-ST-SIDE & 50 & 100 & 0.5 & 92 & 87.76 & 73.57 & 14.19 & 19.3 & $\mathrm{~S} / \mathrm{DB}$ \\
\hline B1-ST-U & 50 & 100 & 0.5 & 92 & 98.36 & 73.57 & 24.79 & 33.7 & $\mathrm{~S} / \mathrm{DB}$ \\
\hline B1-CON-SIDE & 1 & 1 & 1 & 93 & 96.86 & 73.57 & 23.29 & 31.7 & $\mathrm{~S} / \mathrm{DB}$ \\
\hline B1-CON-U & 1 & 1 & 1 & 93 & 109 & 73.57 & 35.43 & 48.2 & $\mathrm{FC}$ \\
\hline
\end{tabular}

Notation:

$\mathrm{w}_{\mathrm{f}}=$ width of CFRP strip laminate

$\mathrm{s}_{\mathrm{f}}=$ spacing of CFRP strip laminate

$\mathrm{V}_{\mathrm{u}, \mathrm{exp}}=$ experimental ultimate shear strength

$\mathrm{V}_{\mathrm{c}}=$ shear strength due to concrete

$\mathrm{V}_{\mathrm{s}}=$ shear strength due to steel stirrups

$\mathrm{V}_{\text {frp }}=$ shear strength due to CFRP

$\mathrm{S}=$ diagonal tension shear failure

$\mathrm{DB}=$ debonding failure of the FRP strips/sheets

$\mathrm{FC}=$ flexural concrete compression failure

Two types of wrapping schemes are used, namely 2-sides labelled "SIDE" and U-wrapped labelled "U". Beams strengthened with continuous CFRP sheet are labelled "CON" and beams strengthened with CFRP strips (strip width, $\mathrm{w}_{\mathrm{f}}=50 \mathrm{~mm}$ and strip spacing, $\mathrm{s}_{\mathrm{f}}=100 \mathrm{~mm}$ ) are labelled "ST". For example beam specimen B1-ST-SIDE featured a beam strengthened with 2-sides-bonded CFRP strips with $50 \mathrm{~mm}$ wide strips spaced at $100 \mathrm{~mm}$.

The CFRP composite used in this test programme is a unidirectional woven carbon fibre fabric SikaWrap 231C, and epoxy-bonded over the beam surface using the Sikadur 330 adhesive. The dry CFRP fabric has a design thickness of $0.127 \mathrm{~mm}$, an ultimate tensile strength of $4900 \mathrm{~N} / \mathrm{mm}^{2}$ and an elastic modulus of $230,000 \mathrm{~N} / \mathrm{mm}^{2}$. Details on the surface preparation and application can be found in the manufacturer's product data sheet [16].

\subsection{Test Setup and Instrumentation}

All beams are tested under four-points loading configuration, as shown in Fig. (2). The clear span between supports is $1600 \mathrm{~mm}$ long. The load is applied at a shear span of $650 \mathrm{~mm}$, which corresponds to shear span-to-effective depth ratio $(\mathrm{a} / \mathrm{d})$ of 3.27 .

The beam specimens are properly instrumented in order to obtain as much data as possible. Three linear variable differential transformers (LVDTs) are installed underneath the beam soffit at the mid-span and load points to measure the vertical deflections. Electrical resistance strain gauges are installed internally on the longitudinal reinforcement, on the steel stirrups, and externally on the CFRP laminates to measure local strains. The relative position of the strain gauges are shown in Fig. (2). It should be noted that in order to study the shear interaction between internal stirrups and external CFRP, the strain gauges on the FRP (F1, F3, F6 and F8 shown in Fig. (2)) are purposely arranged to be in coincident with the strain gauges on the steel stirrups (S1, S2, S3 and S4). 


\section{EXPERIMENTAL RESULTS AND DISCUSSION}

\subsection{Strength and Modes of Failure}

The ultimate shear strength of the beams obtained from the experiment and their respective modes of failure are summarised in Table 1. The crack patterns in each beam are shown in Fig. (3).

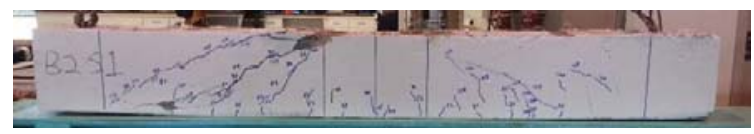

(a) B1

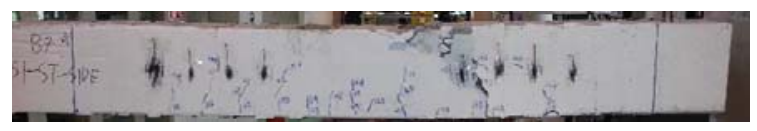

(b) B1-ST-SIDE

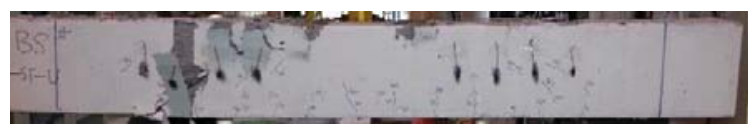

(c) B1-ST-U

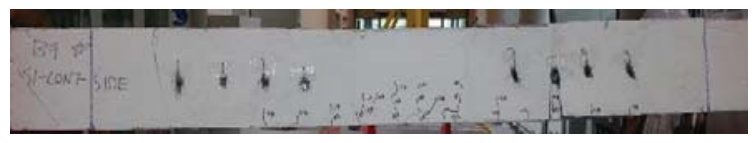

(d) B1-CON-SIDE

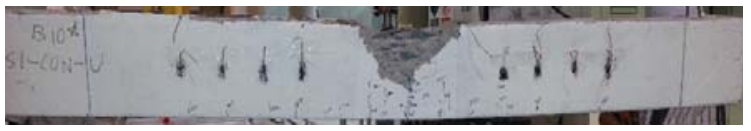

(e) B1-CON-U

Fig. (3). Crack patterns and modes of failure.

Beam B1 is a non-strengthened beam and was found to fail at the ultimate shear strength of $73.57 \mathrm{kN}$. This beam represents the combined contribution of concrete and steel stirrups, therefore is consider as the control specimen in this study. The failure mode of this beam is shear failure with diagonal tension crack along the shear span, as indicated in Fig. (3a).

All strengthened beams, except B1-CON-U, failed in premature debonding of the CFRP laminates followed by diagonal tension shear failure. It was observed that the post-failure behaviour between beams strengthened with CFRP strips and continuous sheets are different. For CFRP strips, with local strip debonding happened, adjacent CFRP strips will come in action to engage and restrain further crack propagation. Most of the time, noticeable failure warning can be observed before utter collapse of the beams, as demonstrated in B1-ST-SIDE and B1-ST-U. In contrast, beam B1-CONSIDE with continuous CFRP sheets failed in brittle and sudden mode of failure once local debonding of sheet initiated.

It is proved without a doubt that externally bonded CFRP laminates are able to enhance the shear strength of the beams. The percentage gain in shear strength due to CFRP strengthening range from $19 \%$ to $48 \%$ depending on the types of strengthening scheme provided. It has shown that U-wrapped performs better than 2-sides bonded, and continuous CFRP sheet outperforms CFRP strips in term of shear strength.

The highest gain of shear strength is obtained from beam B1-CON-U. It failed at the ultimate shear strength of 109 $\mathrm{kN}$, which corresponds an increase of $48.2 \%$ compared with beam B1. This beam exhibited a flexural compression failure mode with concrete crushing at the mid-span top of the beam. 


\subsection{Deflection Responses}

The load deflection response of the beams is plotted in Fig. (4). As can be seen that beam B1, B1-ST-SIDE and B1ST-U undergo similar initial stiffness up to a shear strength level of $40 \mathrm{kN}$. This level of load also marks the initiation of diagonal shear cracks. As can be noticed from Fig. (4), transverse stirrups in beam B1 begin to activate only after that level of loading.

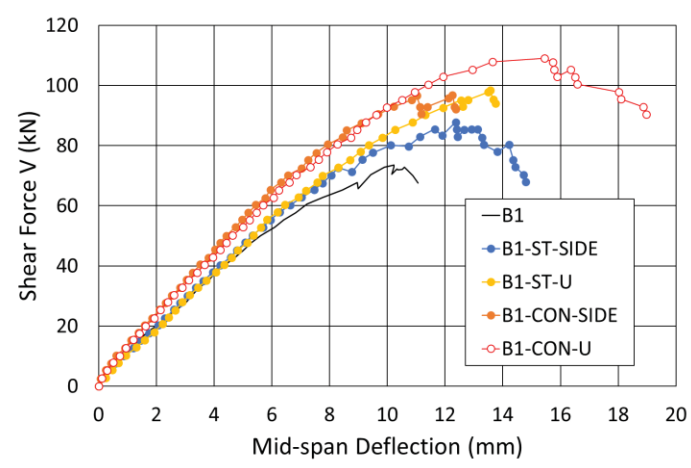

Fig. (4). Load versus mid-span deflection curves.

CFRP strips are able to restrain widening and propagation of the diagonal crack. As demonstrated on beam B1-STSIDE and B1-ST-U, both beams continue to sustain loads and maintain their relative stiffness after passing the diagonal shear cracking load. Especially on beam B1-ST-U, due to better anchorage provided by U-wrapped, it is able to sustain even higher loads compared with beam B1-ST-SIDE.

It can be seen that beams strengthened with continuous CFRP sheets (B1-CON-SIDE and B1-CON-U) exhibit greater stiffness than beams strengthened with CFRP strips (B1-ST-SIDE and B1-ST-U). This is mainly attributed to the effect of the continuity of the continuous CFRP sheets. Experimental tests by Mofidi and Chaallal [4, 5] confirmed this observation as well. As a whole, beam B1-CON-U with continuous CFRP sheets and U-wrapped scheme achieved the highest stiffness and failure load.

\subsection{Strain Responses}

\subsubsection{Transverse Stirrups Strain}

The strain responses of the transverse stirrups are shown in Fig. (5a and b). Each beam is provided with two strain results, which represents the measured strain responses at the shear span. The measured strain values vary considerably depending on the distribution and interception of the main cracks. And also all beams are instrumented symmetrically. Therefore, the strain values presented in Fig. (5) are based on the maximum measured values. Each curve is labelled with their beam designation followed by a bracket denotes the strain gauge position shown in Fig. (2).

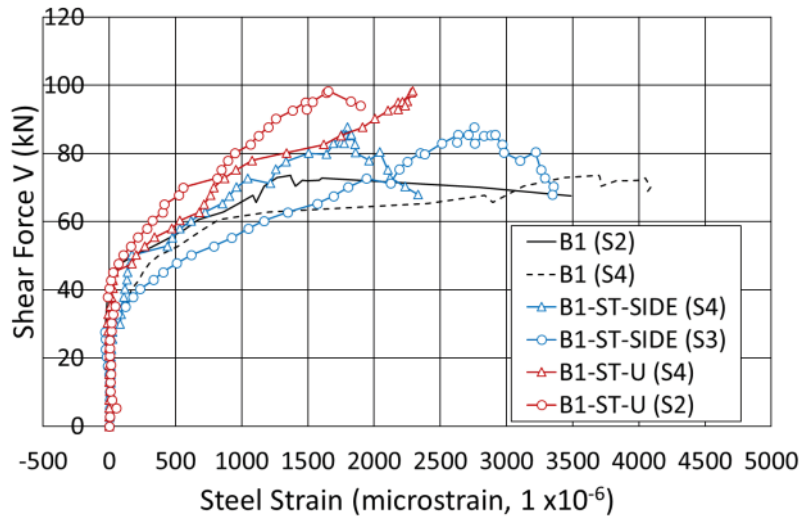

(a) CFRP Strips

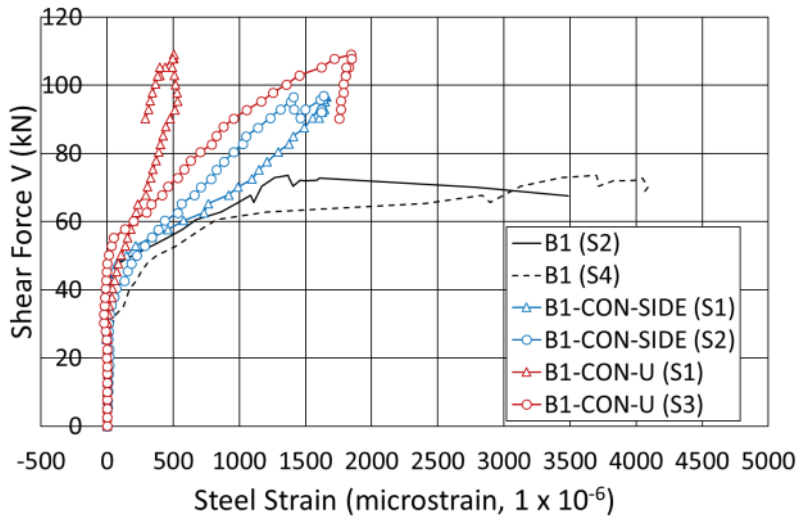

(b) CFRP Continuous Sheets

Fig. (5). Load versus steel strain curves for transverse stirrups. 
Before the occurrence of diagonal cracks, internal stirrups are eventually unstressed and did not contribute to the shear resistance. The stirrups begin to activate only after passing the diagonal shear cracking load. For control beam B1, the diagonal shear cracking load occurred at a shear force of approximately $25 \mathrm{kN}$, whereas for strengthened beams they occurred approximately between 30 and $55 \mathrm{kN}$.

Generally similar to the findings obtained by Bousselham and Chaallal [8], the addition of CFRP reduces the extent of the strain in the transverse stirrups. As shown in both Fig. (5a and $\mathbf{b})$, the strain level in the strengthened beams are generally lower than the control beam B1. Especially for beams strengthened with continuous sheets Fig. (5b), it can be observed that they undergo much lesser strain in the transverse stirrups (less than $0.002(2000 \mu \varepsilon)$ at failure) compare with CFRP strips.

Also, it is interesting to note that, regardless of CFRP strips or continuous sheets, beams with U-wrapped scheme experience lesser transverse stirrup strain than those with 2-sides scheme. Based on the observations, obviously it is evident that the effect due to the continuity of sheets and good anchorage condition as in U-wrapped help to restrain widening of diagonal cracks, ensure greater CFRP contribution to the shear resistance and subsequently ease the strain in the transverse stirrups.

\subsubsection{CFRP Strain}

Fig. (6a and b) presents the CFRP strains for the strengthened beams. As all beams are instrumented symmetrically, therefore only the strain results that correspond to the shear failure side are plotted in Fig. (6). Two CFRP strain results that coincide with the strain gauge positions of transverse stirrups are presented in each beam. There are either F1, F3 or F6, F8, see Fig. (2). Except for B1-CON-U where it failed in flexural compression failure, so only maximum measured strain values are chosen from either side of the shear span.

Similar to transverse stirrups, the strain responses of CFRP are initially unstressed. After the occurrence of diagonal crack, the strain in the CFRP began to increase dramatically. It may be of interest to note that generally the strain attained by beams strengthened with continuous sheets are higher than beams with CFRP strips. Take for instance in B1-CON-U, strain gauge no F1 and F6 undergo more strains than the B1-ST-U strain gauge no F1 and F3, likewise between B1-CON-SIDE and B1-ST-SIDE.

Generally, strain responses that adjacent to applied load (strain gauge no F3 or F6) experience more deformation than those close to the support (strain gauge no F1 or F8). It was found that the maximum strain values attained in BTST-U (F3), B1-CON-SIDE (F6) and B1-CON-U (F6) were all exceeded $0.005(5000 \mu \varepsilon)$. It should be noted that current design guidelines limit the maximum allowable FRP strain value to a certain threshold value in order to maintain the integrity of concrete and prevent aggregate interlock failure. For instance, ACI 440.2R-08 [10] and TR 55 [11] have set the limit to 0.004, meanwhile CNR-DT 200 [12] and fib Bulletin 14 [13] have set the limit to 0.005 and 0.006 respectively.

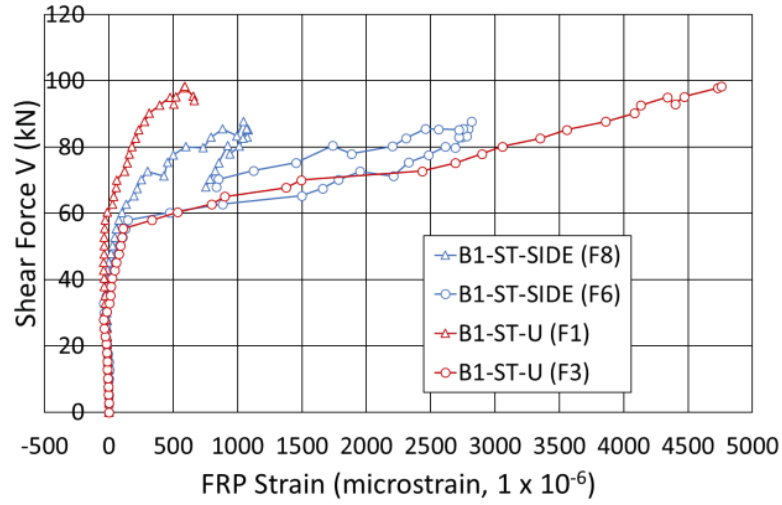

(a) CFRP Strips

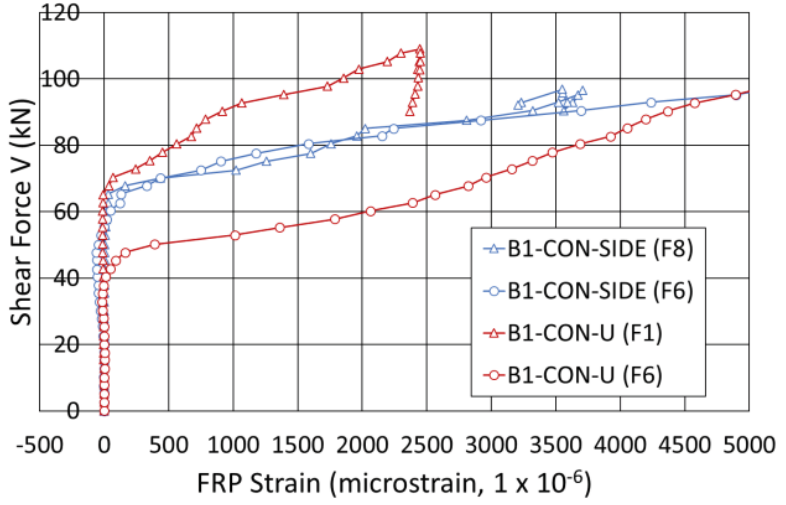

(b) CFRP Continuous Sheets

Fig. (6). Load versus CFRP strain curves.

On the basis of the results obtained, it is evident that the limits set by the current design guidelines appear to be conservative. A Similar observation is also reported by Mofidi and Chaallal [4]. 


\subsubsection{Strain Interaction Between Transverse Stirrups and CFRP}

The strain interaction curves between transverse stirrups and CFRP are presented in Fig. (7). It should be noted that these strain curves are obtained from both Figs. (5 and 6). Based on the observation, the following points can be made:

- Beams strengthened with continuous FRP sheets and U-wrapped scheme contributes greater to shear resistance than with strips and 2-sides scheme.

- With above mentioned strengthening condition, large dilation of strains occurred in CFRP compared with the transverse stirrup, as shown in beam B1-CON-SIDE, B1-CON-U and B1-ST-U.

- Beam B1-ST-SIDE is prone to premature debonding of FRP laminate. From Fig. (7c), it could be noticed that CFRP strains undergo either lesser or similar to the transverse stirrups.

- It is interesting to note that maximum transverse stirrup strains at failure for beam B1-CON-SIDE, B1-CON-U and B1-ST-U were found in the range between $0.0015(1500 \mu \varepsilon)$ and $0.002(2000 \mu \varepsilon)$.

- The results clearly show that the effect of externally bonded FRP preserves the integrity of internal transverse stirrups.
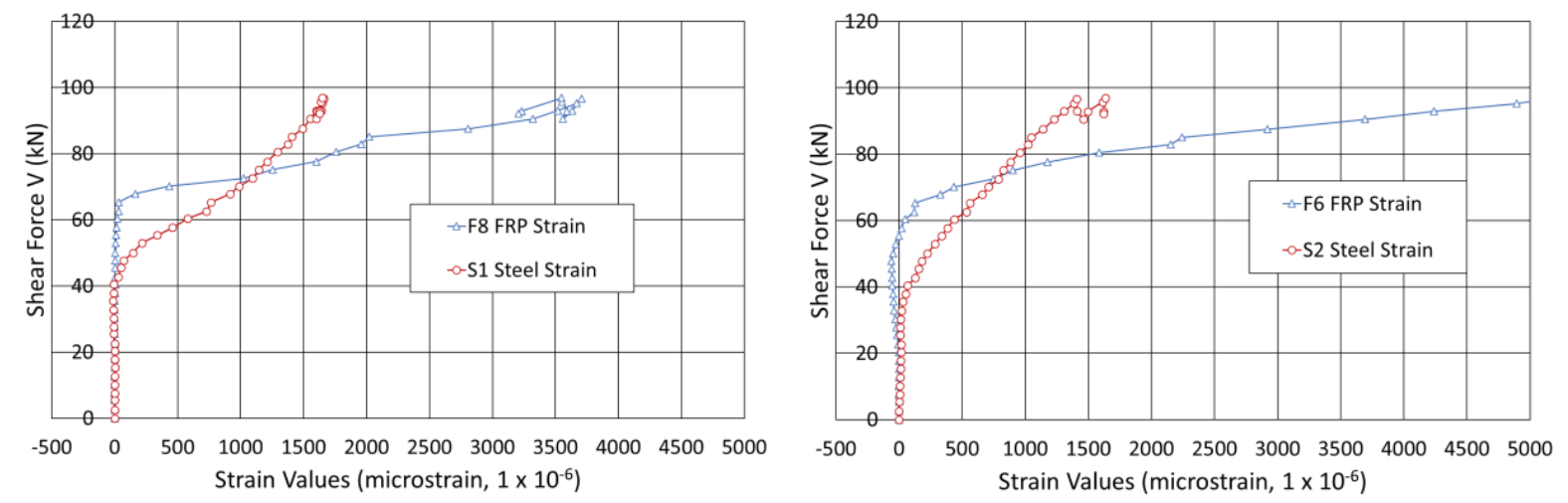

(a) B1-CON-SIDE
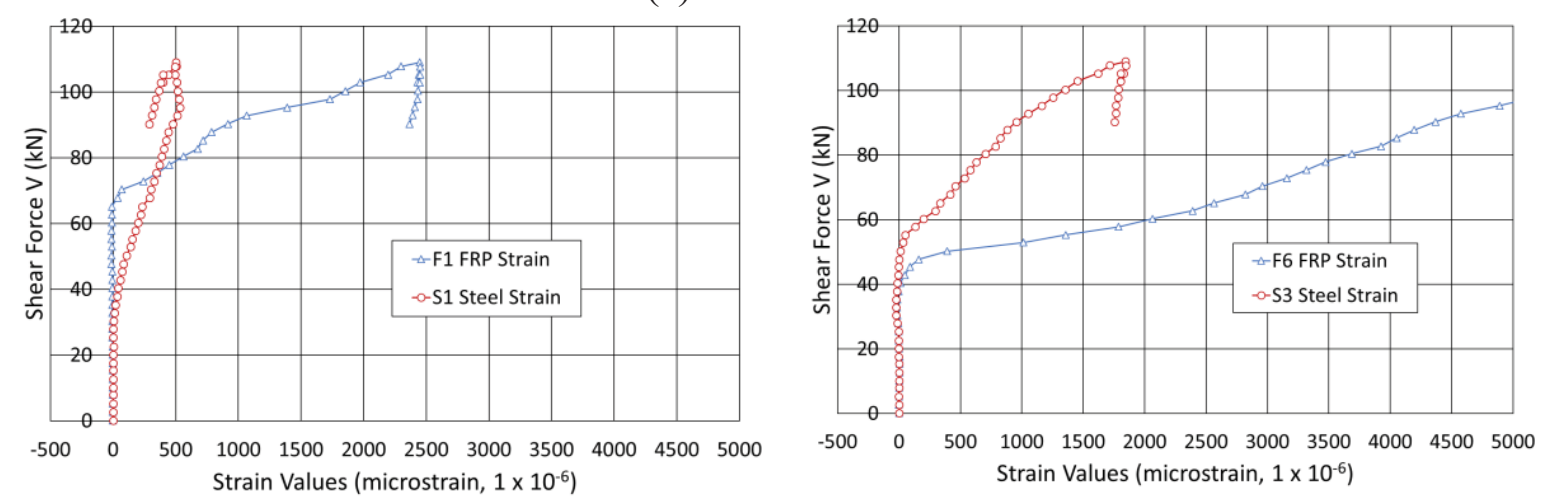

(b) B1-CON-U
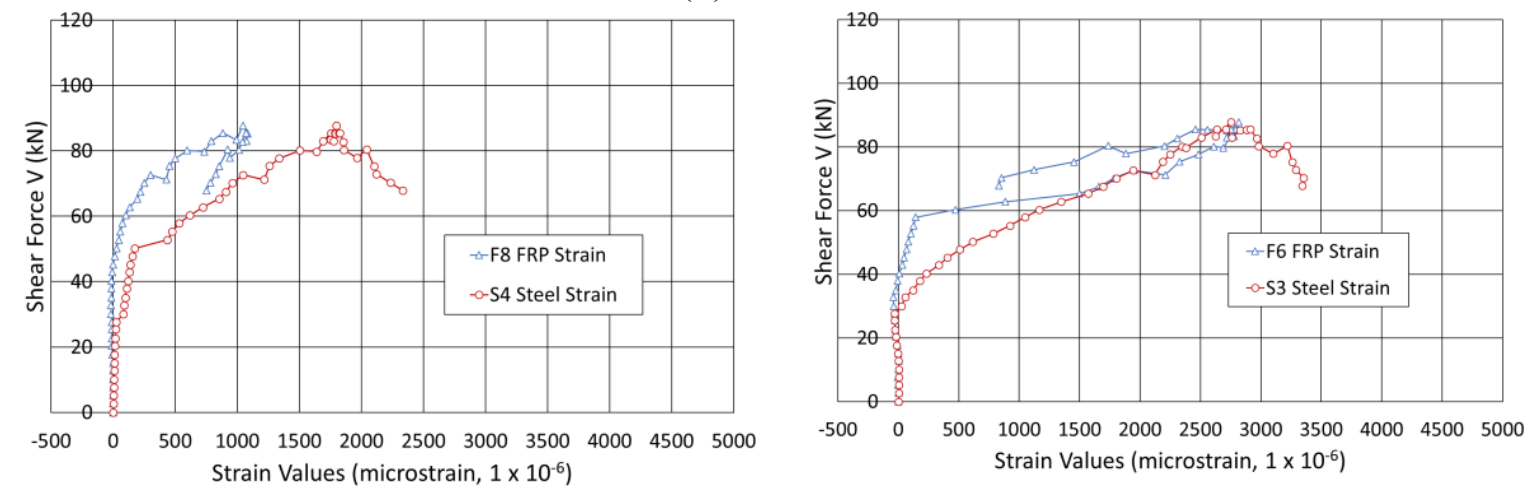

(c) B1-ST-SIDE 

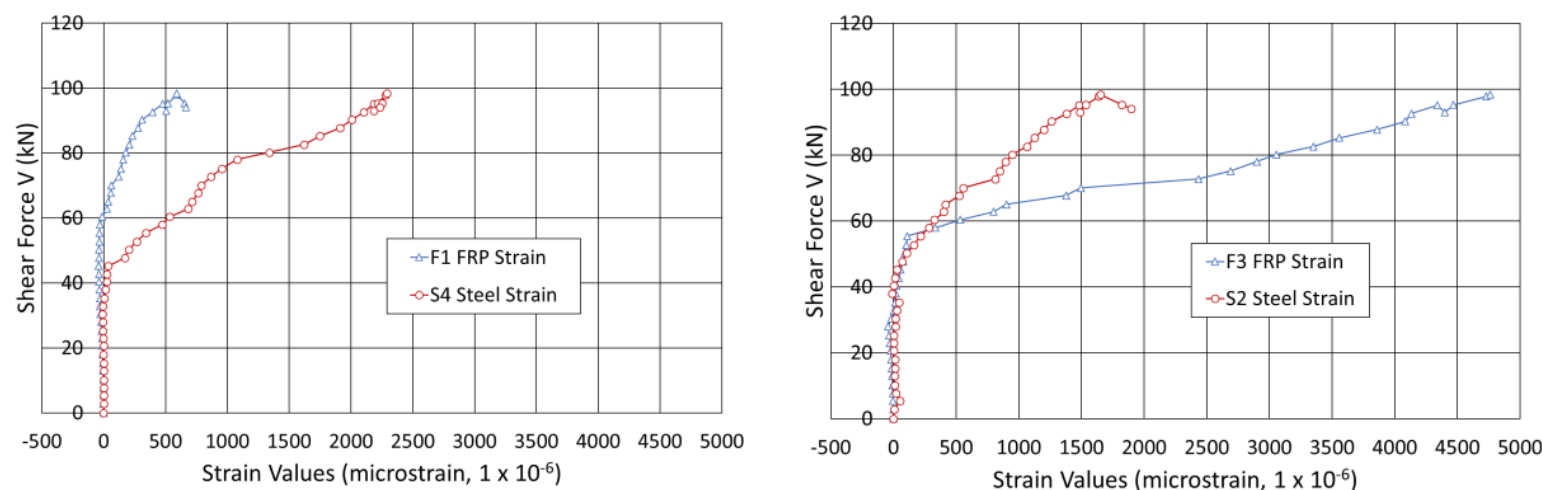

(d) B1-ST-U

Fig. (7). Strain interaction curves between transverse stirrups and CFRP.

\section{CONCLUSION}

This paper presents the preliminary results obtained experimentally to investigate the shear interaction between internal transverse stirrups and externally bonded CFRP systems in RC beams. As part of the scope, five beams strengthened in shear by externally bonded CFRP strips and sheets were tested. Based on the results obtained, the following conclusions can be drawn:

- Beam B1-CON-U with continuous CFRP sheets and U-wrapped scheme achieved the highest ultimate shear strength, which corresponds to an increase of $48.2 \%$ compared with control beam B1. This beam also exhibited the highest stiffness and failed in flexural compression compared with others.

- The results obtained indicated that addition of externally bonded CFRP preserves the integrity of internal transverse stirrups. With CFRP eases the strain in the transverse stirrups substantially, especially for U-wrapped scheme.

- With continuous FRP sheets and U-wrapped scheme, greater FRP contribution to the shear resistance can be expected. Fig. (7a-d) clearly reflect the substantial increase in the CFRP strains.

\section{CONFLICT OF INTEREST}

The authors confirm that this article content has no conflict of interest.

\section{ACKNOWLEDGEMENTS}

The research presented in this paper was financially supported by the Ministry of Education (MOE) Malaysia under the Fundamental Research Grant Scheme [FRGS/1/2014/TK02/UTP/02/5]. All authors would like to thank and express their gratitude and sincere appreciation to the MOE for providing financial support for the research.

\section{REFERENCES}

[1] ASCE-ACI Committee 445 on Shear and torsion, "Recent approaches to shear design of structural concrete", J. Struct. Eng., vol. 124, no. 12, pp. 1375-1417, 1998.

[http://dx.doi.org/10.1061/(ASCE)0733-9445(1998)124:12(1375)]

[2] G.M. Chen, J.G. Teng, J.F. Chen, and O.A. Rosenboom, "Interaction between steel stirrups and shear strengthening FRP strips in RC beams", J. Compos. Constr., vol. 14, no. 5, pp. 498-509, 2010.

[http://dx.doi.org/10.1061/(ASCE)CC.1943-5614.0000120]

[3] G.M. Chen, J.G. Teng, and J.F. Chen, "Shear strength model for FRP-strengthened RCC beams with adverse FRP-steel interaction", J. Compos. Constr., vol. 17, no. 1, pp. 50-66, 2013.

[http://dx.doi.org/10.1061/(ASCE)CC.1943-5614.0000313]

[4] A. Mofidi, and O. Chaallal, "Effect of steel stirrups on shear resistance gain due to externally bonded fiber-reinforced polymer strips and sheets", ACI Struct. J., vol. 111, no. 2, pp. 353-362, 2014.

[5] A. Mofidi, and O. Chaallal, "Shear strengthening of RC beams with externally bonded FRP composites: Effect of strip-width-to-strip-spacing ratio", J. Compos. Constr., vol. 15, no. 5, pp. 732-742, 2011.

[http://dx.doi.org/10.1061/(ASCE)CC.1943-5614.0000219] 
[6] A. Mofidi, and O. Chaallal, "Tests and design provisions for reinforced-concrete beams strengthened in shear using FRP sheets and strips", Int. J. Concr. Struct. Mater., vol. 8, no. 2, pp. 117-128, 2014. [http://dx.doi.org/10.1007/s40069-013-0060-1]

[7] A. Bousselham, and O. Chaallal, "Shear strengthening reinforced concrete beams with fibre-reinforced polymer: Assessment of influencing parameters and required research", ACI Struct. J., vol. 101, no. 2, pp. 219-227, 2004.

[8] A. Bousselham, and O. Chaallal, "Effect of transverse steel and shear span on the performance of RC beams strengthened in shear with CFRP", Compos., Part B Eng., vol. 37, pp. 37-46, 2006. [http://dx.doi.org/10.1016/j.compositesb.2005.05.012]

[9] A. Bousselham, and O. Chaallal, "Mechanisms of shear resistance of concrete beams strengthened in shear with externally bonded FRP", $J$. Compos. Constr., vol. 12, no. 5, pp. 499-512, 2008.

[http://dx.doi.org/10.1061/(ASCE)1090-0268(2008)12:5(499)]

[10] ACI 440.2R-08, Guide for the Design and Construction of Externally Bonded FRP Systems for Strengthening Concrete Structures, American Concrete Institute: Farmington Hills, 2008.

[11] TR 55, Design Guidance for Strengthening Concrete Structures Using Fibre Composite Materials, $3^{\text {rd }}$ Technical Report No. 55: The Concrete Society UK, 2012.

[12] CNR-DT 200/2004, Guide for the Design and Construction of Externally Bonded FRP Systems for Strengthening Existing Structures., Italian National Research Council (CNR): Rome, 2004.

[13] fib (CEB-FIP) Bulletin 14, Externally Bonded FRP Reinforcement for RC Structures, Design and use of externally bonded fibre reinforced polymer reinforcement (FRP.EBR) for reinforced concrete structures (Technical Report), International Federation for Structural Concrete (fib), 2001.

[14] E. Grande, M. Imbimbo, and A. Rasulo, "Effect of transverse steel on the response of RC beams strengthened in shear by FRP: Experimental study", J. Compos. Constr., vol. 13, no. 5, pp. 405-414, 2009.

[http://dx.doi.org/10.1061/(ASCE)1090-0268(2009)13:5(405)]

[15] C. Pellegrino, and C. Modena, "Fiber reinforced polymer shear strengthening of reinforced concrete beams with transverse steel reinforcement", J. Compos. Constr., vol. 6, no. 2, pp. 104-111, 2002.

[http://dx.doi.org/10.1061/(ASCE)1090-0268(2002)6:2(104)]

[16] A. Baier, Method of Statement for SikaWrap Manual Dry Application, Sika Services AG, Ref 850 41 02, 2011.

(C) 2017 Teo et al.

This is an open access article distributed under the terms of the Creative Commons Attribution 4.0 International Public License (CC-BY 4.0), a copy of which is available at: https://creativecommons.org/licenses/by/4.0/legalcode. This license permits unrestricted use, distribution, and reproduction in any medium, provided the original author and source are credited. 